\title{
Multi-objective optimization of single pass turning using performance diagrams
}

\author{
Miroslav Radovanovic ${ }^{1, *}$ \\ ${ }^{1}$ University of Nis, Faculty of Mechanical Engineering, 18000 Nis, Serbia
}

\begin{abstract}
Maximization of productivity and minimization of cost with acceptable quality of the parts are the most important goals of the production. In machining multi-objective optimization is a real problem. For solving this problem modern optimization methods are used. In this paper is presented a multi-objective optimization of single-pass turning of stainless steel with coated carbide tool using performance diagrams.
\end{abstract}

\section{Introduction}

Optimization of cutting performances is one of the most important problems in machining processes. Multi-objective optimization provides optimal or near-optimal solution for two or more objectives in machining process. Number of researchers has studied multiobjective optimization in turning operations. Kubler F. et al. in [1] studied turning of $42 \mathrm{CrMo} 4$ using coated carbide cutting tool. They investigated the effect of depth of cut, feed rate and cutting speed on machining time, tool wear and process energy. For solving the multi-objective optimization problem with three objectives they applied GA based non dominated sorting algorithm-II (NSGA-II). Soni V. et al. in [2] studied turning of aluminum using carbide cutting tool. They investigated the effect of depth of cut, feed rate and cutting speed on material removal rate and surface roughness. For solving the multiobjective optimization problem with two objectives they applied Multi Objective Genetic Algorithm (MOGA). Abbas A. et al. in [3] studied turning of J-steel using uncoated carbide cutting tool. They investigated the effect of depth of cut, feed rate and cutting speed on machining time and surface roughness. For solving the multi-objective optimization problem with two objectives they applied Multi-objective Efficient Global Algorithm. Dhandapani K. et al. in [4] studied turning of AISI 4340 using uncoated carbide cutting tool. They investigated the effect of depth of cut, feed rate and cutting speed on material removal rate, flank wear and surface roughness. For solving the multi-objective optimization problem with three objectives they applied GA based non dominated sorting algorithm-II (NSGA-II). Soury E. et al. in [5] studied turning of St 37 using high speed steel cutting tool. They investigated the effect of depth of cut, feed rate, cutting speed, tool rake angle and nose radius on tool life and surface roughness. For solving the multiobjective optimization problem with two objectives they applied the optimization software program based on Visual Basic.

\footnotetext{
*Corresponding author: mirado@masfak.ni.ac.rs
} 
In this paper is presented a multi-objective optimization of single-pass turning of stainless steel with coated carbide tool. For solving the multi-objective optimization problem with two objectives (material removal rate and machining cost), three factors (tool nose radius, feed rate and cutting speed) and nonlinear constraints (surface roughness, tool life and cutting power), performance diagrams are used.

\section{Multi-objective optimization}

Procedure of solving the multi-objective optimization problem has four phases. First phase is selecting objectives, factors and constraints. Second phase is determining optimization problem. Third phase is selection of method for solution the optimization problem. Fourth phase is solution the optimization problem. First phase in multi-objective optimization is selection of objectives, factors and constraints. Two objectives, material removal rate and machining cost, and three factors, tool nose radius, feed rate and cutting speed, are selected. For nonlinear constraints, surface roughness, tool life and cutting power are used.

Tool life is performance of the cutting tool from which depends continual work. Relation between the tool life and the cutting factors is expressed with the Taylor's formula.

$$
\mathrm{T}=\frac{\mathrm{C}_{\mathrm{T}}}{\mathrm{a}_{\mathrm{p}}^{\mathrm{r}} \mathrm{f}^{\mathrm{m}} \mathrm{v}_{\mathrm{c}}^{\mathrm{p}}}
$$

Where: $\mathrm{T}(\mathrm{min})$ - tool life, $\mathrm{a}_{\mathrm{p}}(\mathrm{mm})$ - depth of cut, $\mathrm{f}(\mathrm{mm} / \mathrm{rev})$ - feed rate, $\mathrm{v}_{\mathrm{c}}(\mathrm{m} / \mathrm{min})$ cutting speed, $\mathrm{C}_{\mathrm{T}}, \mathrm{r}, \mathrm{m}$ and $\mathrm{p}-$ empirical constants relevant to a specific tool-workpiece combination.

Surface roughness is performance of the workpiece which must be satisfy. Ordinarily, average surface roughness is used.

$$
\mathrm{R}_{\mathrm{a}}=32 \frac{\mathrm{f}^{2}}{\mathrm{r}_{\varepsilon}}
$$

Where: $\mathrm{R}_{\mathrm{a}}(\mu \mathrm{m})$ - surface roughness, $\mathrm{f}(\mathrm{mm} / \mathrm{rev})$ - feed rate, $\mathrm{r}_{\varepsilon}(\mathrm{mm})$ - tool nose radius.

Cutting power is important in view of available machine tool power.

$$
\begin{gathered}
P_{c}=\frac{F_{c} v_{c}}{60000}=\frac{k_{c 1.1} a_{p} f^{1-m_{c}} v_{c}}{60000(\sin \kappa)^{m_{c}}} \\
P_{c} \leq \eta P_{m}
\end{gathered}
$$

Where: $\mathrm{P}_{\mathrm{c}}(\mathrm{kW})$ - cutting power, $\mathrm{k}_{\mathrm{c} 1.1}\left(\mathrm{~N} / \mathrm{mm}^{2}\right)$ - unit specific cutting force, $\mathrm{m}_{\mathrm{c}}$ - exponent of specific cutting force, $\kappa$ - cutting edge angle, $\eta$ - efficiency, $\mathrm{P}_{\mathrm{m}}$ - machine power (main motor power).

Machining time for single pass turning is:

$$
\mathrm{t}_{\mathrm{m}}=\frac{\mathrm{L}}{\mathrm{fn}}=\frac{\pi \mathrm{DL}}{1000 \mathrm{fv}_{\mathrm{c}}}
$$

Where: $\mathrm{t}_{\mathrm{m}}$ (min)- machining time, $\mathrm{L}(\mathrm{mm})$ - cutting length, $\mathrm{f}(\mathrm{mm} / \mathrm{rev})$ - feed, $\mathrm{n}$ (rpm) spindle speed, D $(\mathrm{mm})$ - working diameter, $\mathrm{v}_{\mathrm{c}}(\mathrm{m} / \mathrm{min})$ - cutting speed.

Material removal rate is volume of removed material in unit time. 


$$
\operatorname{MRR}=\mathrm{a}_{\mathrm{p}} \mathrm{fv}_{\mathrm{c}}
$$

Where: MRR $\left(\mathrm{cm}^{3} / \mathrm{min}\right)$ - material removal rate, $\mathrm{a}_{\mathrm{p}}(\mathrm{mm})$ - depth of cut, $\mathrm{f}(\mathrm{mm} / \mathrm{r})$ - feed, $\mathrm{v}_{\mathrm{c}}$ $(\mathrm{m} / \mathrm{min})$ - cutting speed.

Machining cost for machining working diameter on cutting length is:

$$
\mathrm{C}=\mathrm{C}_{\mathrm{r}} \mathrm{t}_{\mathrm{n}}+\mathrm{C}_{\mathrm{r}} \mathrm{t}_{\mathrm{m}}+\frac{\mathrm{t}_{\mathrm{m}}}{\mathrm{T}}\left(\mathrm{C}_{\mathrm{r}} \mathrm{t}_{\mathrm{d}}+\mathrm{C}_{\mathrm{a}}\right)
$$

Where: $C(E U R)$ - machining cost per piece, $C_{r}(E U R)$ - labor plus overhead cost, $t_{n}(\min )$ - nonproductive time, $\mathrm{t}_{\mathrm{m}}(\mathrm{min})$ - machining time, $\mathrm{T}(\mathrm{min})-$ tool life, $\mathrm{t}_{\mathrm{d}}(\mathrm{min})-$ tool changing time, $\mathrm{C}_{\mathrm{a}}(\mathrm{EUR})$ - tool cost per cutting edge.

Machining cost for turning, according to (1) and (3), is:

$$
\begin{gathered}
\mathrm{C}=\mathrm{C}_{0}+\mathrm{C}_{1} \mathrm{f}^{-1} \mathrm{v}_{\mathrm{c}}^{-1}+\mathrm{C}_{2} \mathrm{a}_{\mathrm{p}}^{\mathrm{r}} \mathrm{f}^{\mathrm{m}-1} \mathrm{v}_{\mathrm{c}}^{\mathrm{n}-1} \\
\mathrm{C}_{0}=\mathrm{C}_{\mathrm{r}} \mathrm{t}_{\mathrm{n}}, \mathrm{C}_{1}=\frac{\pi \mathrm{DLC} \mathrm{C}_{\mathrm{r}}}{1000}, \mathrm{C}_{2}=\frac{\pi \mathrm{DL}\left(\mathrm{C}_{\mathrm{r}} \mathrm{t}_{\mathrm{d}}+\mathrm{C}_{\mathrm{a}}\right)}{1000 \mathrm{C}_{\mathrm{T}}}, \mathrm{C}_{\mathrm{a}}=\frac{\mathrm{C}_{\mathrm{wp}} \mathrm{n}_{\mathrm{p}}}{\mathrm{n}_{\mathrm{tp}}}\left(1+\frac{\mathrm{z}_{\mathrm{b}}}{2}\right)+\frac{\mathrm{C}_{\mathrm{wh}}}{\mathrm{n}_{\mathrm{th}}}+\frac{\mathrm{C}_{\mathrm{we}}}{\mathrm{n}_{\mathrm{te}}}+\mathrm{C}_{\mathrm{wv}}
\end{gathered}
$$

Where: $\mathrm{C}_{\mathrm{wp}}$ (EUR) - cost of insert, $\mathrm{n}_{\mathrm{p}}$ - number of cutting edges in machining, $\mathrm{n}_{\mathrm{tp}}$ - number of useful insert cutting edges, $\mathrm{z}_{\mathrm{b}}$ - factor of fractures of cutting edge, $\mathrm{z}_{\mathrm{b}}=0.2-0.4, \mathrm{C}_{\mathrm{wh}}$ (EUR) - cost of tool holder, $\mathrm{n}_{\mathrm{th}}$ - number of tool life (cutting edge) to endure one tool holder, $\mathrm{C}_{\mathrm{we}}$ (EUR) - cost of tool holder parts, $\mathrm{C}_{\mathrm{we}}=(0.2-0.3) \mathrm{C}_{\mathrm{wh}}, \mathrm{n}_{\mathrm{te}}$ - number of tool life (cutting edge) to endure tool holder parts, $\mathrm{n}_{\mathrm{te}}=(0.15-0.30) \mathrm{n}_{\mathrm{th}}, \mathrm{C}_{\mathrm{wv}}$ (EUR) - cost of preparing tool.

The proposed mathematical model of optimization consists of two objectives, nonlinear constraints and bounds. The mathematical model of multi-objective optimization for singlepass turning has the next form:

- Objective functions:

$$
\begin{aligned}
& \max , M R R=a_{p} f_{c} \\
& \min , C=C_{0}+C_{1} f^{-1} v_{c}^{-1}+C_{2} a_{p}^{r} f^{m-1} v_{c}^{n-1}
\end{aligned}
$$

- Constraints:

$$
\begin{array}{ll}
\mathrm{R}_{\mathrm{a}} \leq \mathrm{R}_{\mathrm{a}, \max } & \text { (Constraint related to surface roughness) } \\
\mathrm{T} \geq \mathrm{T}_{\mathrm{e}} & \text { (Constraint related to economical tool life) } \\
\frac{\mathrm{P}_{\mathrm{c}}}{\eta} \leq \mathrm{P}_{\mathrm{m}} & \text { (Constraint related to available machine power) } \\
\pi \mathrm{Dn}_{\min } \leq \mathrm{v}_{\mathrm{c}} \leq \pi \mathrm{Dn} \mathrm{m}_{\max } & \text { (Constraint related to available spindle speed) } \\
\mathrm{v}_{\mathrm{c}, \min } \leq \mathrm{v}_{\mathrm{c}} \leq \mathrm{v}_{\mathrm{c}, \max } & \text { (Constraint related to tool performance) } \\
\mathrm{f}_{1, \min } \leq \mathrm{f} \leq \mathrm{f}_{1, \max } & \text { (Constraint related to available feed on machine) } \\
\mathrm{f}_{2, \min } \leq \mathrm{f} \leq \mathrm{f}_{2, \max } & \text { (Constraint related to tool performance) } \\
\mathrm{r}_{\varepsilon, \min } \leq \mathrm{r}_{\varepsilon} \leq \mathrm{r}_{\varepsilon, \max } & \text { (Constraint related to tool performance) }
\end{array}
$$

One example of optimization is presented. Workpiece is a bar made from austenitic stainless steel X5CrNiMo18 10, diameter of $\mathrm{D}=75 \mathrm{~mm}$, length of $\mathrm{L}=200 \mathrm{~mm}$, unit specific cutting force of $k_{c 1.1}=2600 \mathrm{~N} / \mathrm{mm}^{2}$ and $m_{c}=0.19$. Depth of cut is $a_{p}=3 \mathrm{~mm}$. Machine tool is the universal lathe "Potisje PA-C30" with motor power of $\mathrm{P}_{\mathrm{m}}=11 \mathrm{~kW}$ and efficiency of $\eta=0.8$. Spindle speed range is $n=20-2000 \mathrm{rpm}$ and feed range is $\mathrm{f}=0.04-9.16 \mathrm{~mm} / \mathrm{rev}$. Tool holder is PCLNR, cutting edge angle of $\kappa=95^{\circ}$ and rake angle of $\gamma=-6^{\circ}$, with insert CNMG, tool nose radius of $r_{\varepsilon}=\left[\begin{array}{lllll}0.4 & 0.8 & 1.2 & 1.6 & 2.4\end{array}\right] \mathrm{mm}$, grade of IC9025 (Iscar). Recommended 
levels of the cutting factors are: $a_{\mathrm{p}}=0.10-10.00 \mathrm{~mm}, \mathrm{f}=0.05-0.80 \mathrm{~mm} / \mathrm{rev}, \mathrm{v}_{\mathrm{c}, \max }=290 \mathrm{~m} / \mathrm{min}$. Economical tool life is $\mathrm{T}_{\mathrm{e}}=15 \mathrm{~min}$. Surface roughness is $\mathrm{R}_{\mathrm{a}}=12.5 \mu \mathrm{m}$. According to cutting tool performances $\left(\mathrm{f}=0.05-0.80 \mathrm{~mm} / \mathrm{rev}, \mathrm{n}_{\max }=1000 \mathrm{v}_{\mathrm{c}, \max } / \mathrm{D} \pi=1000 \cdot 290 / 75 \pi=1231 \mathrm{rpm}\right)$, useful range of feed rate is $\mathrm{f}=\left[\begin{array}{lllllllll}0.049 & 0.053 & 0.062 & 0.071 & 0.080 & 0.089 & 0.098 & 0.107 & 0.124\end{array}\right.$ $\begin{array}{llllllllllllll}0.142 & 0.160 & 0.178 & 0.196 & 0.214 & 0.249 & 0.285 & 0.321 & 0.357 & 0.392 & 0.428 & 0.499 & 0.571 & 0.642\end{array}$

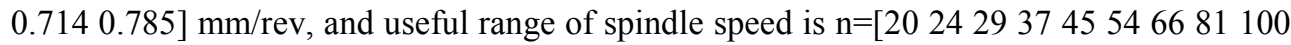
$1201451802053304005006007409101100] \mathrm{rpm}$. Other data are: $\mathrm{C}_{\mathrm{r}}=30 \mathrm{EUR} / \mathrm{h}, \mathrm{t}_{\mathrm{n}}=1$ $\min , \mathrm{t}_{\mathrm{d}}=1 \mathrm{~min}, \mathrm{C}_{\mathrm{wp}}=4.5$ EUR, $\mathrm{n}_{\mathrm{p}}=1, \mathrm{n}_{\mathrm{tp}}=4, \mathrm{z}_{\mathrm{b}}=0.2, \mathrm{C}_{\mathrm{wh}}=50$ EUR, $\mathrm{n}_{\mathrm{th}}=300, \mathrm{C}_{\mathrm{we}}=15 \mathrm{EUR}$, $\mathrm{n}_{\mathrm{te}}=200, \mathrm{C}_{\mathrm{wv}}=0$ EUR.

Tool life equation for turning stainless steel with coated carbide tool is [6]:

$$
\mathrm{T}=\frac{21.873 \cdot 10^{3}}{\mathrm{f}^{0.081} \mathrm{v}_{\mathrm{c}}^{1.348}}
$$

Mathematical model of multi-objective optimization for this example is:

- Objective functions:

$$
\begin{aligned}
& \max , \mathrm{MRR}=3 \mathrm{fv}_{\mathrm{c}} \\
& \min , \mathrm{C}=0.5+23.55 \mathrm{f}^{-1} \mathrm{v}_{\mathrm{c}}^{-1}+0.004 \frac{\mathrm{v}_{\mathrm{c}}^{0.348}}{\mathrm{f}^{0.919}}
\end{aligned}
$$

- Constraints:

$$
\begin{aligned}
& 32 \frac{\mathrm{f}^{2}}{\mathrm{r}_{\varepsilon}} \leq 12.5 \\
& \frac{21.873 \cdot 10^{3}}{\mathrm{f}^{0.081} \mathrm{v}_{\mathrm{c}}^{1.348}} \geq 15 \\
& 0.163 \mathrm{f}^{0.81} \mathrm{v}_{\mathrm{c}} \leq 11 \\
& 4.71 \leq \mathrm{v}_{\mathrm{c}} \leq 290 \\
& 0.049 \leq \mathrm{f} \leq 0.785 \\
& 0.4 \leq \mathrm{r}_{\varepsilon} \leq 2.4
\end{aligned}
$$

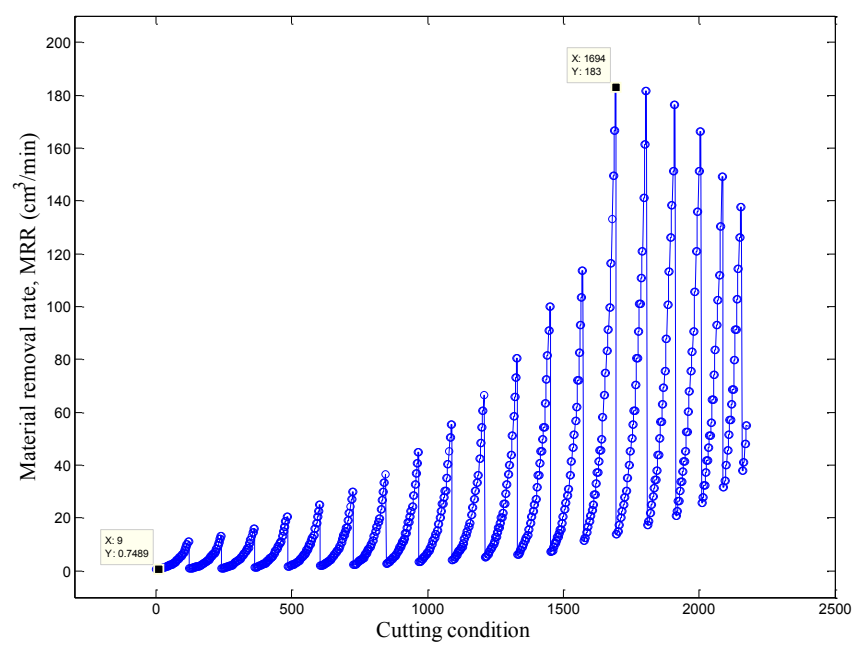

Fig. 1. Material removal rate vs cutting conditions. 
For solving the optimization problem performance diagrams are used. Performance diagrams are drawn for all combinations of tool nose radius, feed rate and spindle speed, with respect to constraints of surface roughness, tool life and machine tool power. In this way 2500 different cutting conditions were obtained. In figure 1 is shown $2 \mathrm{D}$ diagram of material removal rate versus cutting conditions, and in figure 2 is shown $2 \mathrm{D}$ diagram of machining cost versus cutting conditions. Each point in 2D performance diagrams presents one particular cutting condition, i.e. combination of factor levels $\left(r_{\varepsilon}, f, n\right)$.

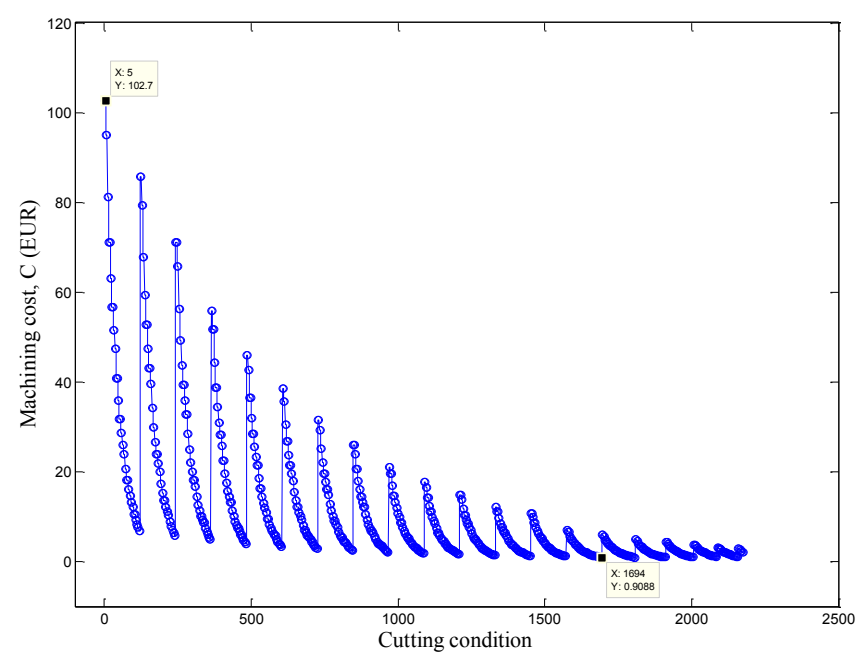

Fig. 2. Machining cost vs cutting conditions.

Based on the performance diagrams, the effects of factors on the objectives can be analyzed. From Figure 1 it can be seen that the point where the material removal rate has maximal value of $183 \mathrm{~cm}^{3} / \mathrm{min}$ corresponds to combination 1694 . From Figure 2 it can see that the point where the machining cost has minimal value of 0.9088 EUR corresponds to the same combination 1694.

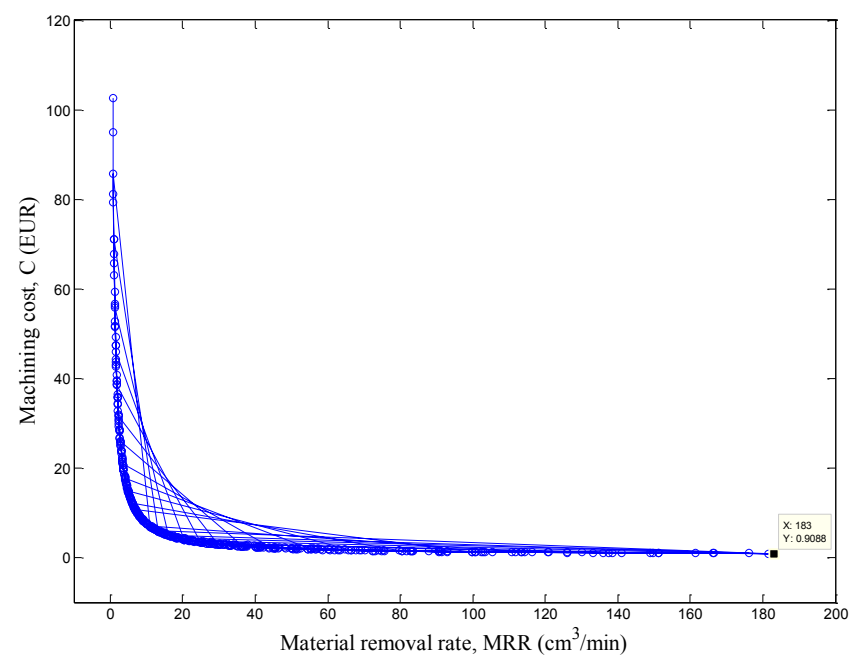

Fig. 3. Machining cost vs material removal rate. 
In Figure 3 is shown the diagram of machining cost versus material removal rate. From Figure 3 it can see global optimum, i.e. the point positioned in the lower right corner, where the material removal rate has maximal value of $183 \mathrm{~cm}^{3} / \mathrm{min}$ and machining cost has minimal value of 0.9088 EUR. This point corresponds to combination of factor levels 1694 with data: $r_{\varepsilon}=2.4 \mathrm{~mm}, \mathrm{f}=0.785 \mathrm{~mm} / \mathrm{rev}$ and $\mathrm{n}=330 \mathrm{rpm}\left(\mathrm{v}_{\mathrm{c}}=77.715 \mathrm{~m} / \mathrm{min}\right)$. For these factor levels material removal rate is maximal $\mathrm{MRR}_{\max }=183 \mathrm{~cm}^{3} / \mathrm{min}$, machining cost is minimal $\mathrm{C}_{\text {min }}=0.908$ EUR, machining time is $\mathrm{t}_{\mathrm{m}}=0.772 \mathrm{~min}$, tool life is $\mathrm{T}=63 \mathrm{~min}$, surface roughness is $\mathrm{Ra}=8.22 \mu \mathrm{m}$ and cutting power is $\mathrm{P}_{\mathrm{c}}=8.33 \mathrm{~kW}$.

\section{Conclusion}

Performance diagrams were used for solving multi-objective optimization in single-pass turning of stainless steel with coated carbide tool. Cutting factors, tool nose radius, feed rate and cutting speed, were selected for maximal material removal rate and minimal machining cost. For factor levels $r_{\varepsilon}=2.4 \mathrm{~mm}, \mathrm{f}=0.785 \mathrm{~mm} / \mathrm{rev}$, and $\mathrm{n}=330 \mathrm{rpm}\left(\mathrm{v}_{\mathrm{c}}=77.715 \mathrm{~m} / \mathrm{min}\right)$ material removal rate is maximal $\mathrm{MRR}_{\max }=183 \mathrm{~cm}^{3} /$ min and machining cost is minimal $\mathrm{C}_{\min }=0.908$ EUR. In this way the performance diagrams can be used as decision making tool in process planning for selection of cutting conditions.

The paper is a result of the technological project TR35034 which is supported by the Ministry of Education, Science and Technological Development of Republic of Serbia.

\section{References}

1. F. Kubler, Procedia CIRP, 29, 822-827 (2015)

2. V. Soni, S. Mondal, B. Singh, IJISET-International Journal of Innovative Science, Engineering \& Technology 1 (3), 418-423 (2014)

3. A. Abbas, K. Hamza, M. Aly, E. Al-Bakhali, Advances in Matterials Science and Engineering, http://dx.doi.org/10.1155/2016/6429160 (2016)

4. K. Dhandapani, P. Vasanthkumar, S. Nagarajan, Journal of Advanced Engineering Research 1 (2), 105-113 (2014)

5. E. Soury, E. Esfahany, A. Shahreza, Indian J Sci Res 1 (2), 54-63 (2014)

6. A. Bubakar, http://etheses.dur.ac.uk/5287/ (1996)

7. M. Madic, M. Radovanovic, P. Jankovic, D. Petkovic, S. Mladenovic, Journal of Production Engineering 19 (2), 1-6 (2016)

8. M. R. Radovanovic, M.M. Radovanovic, Tribological Journal Bultrib 6, 85-90 (2016)

9. D. Petkovic, M. Radovanovic, Journal of Engineering Studies and Research 19 (1), 4755 (2013) 